\section{Ocean Justice: SDG 14 and Beyond}

Chris Armstrong, University of Southampton

Forthcoming in Journal of Global Ethics (2020)

\section{Abstract:}

The ocean is central to our lives, but many of our impacts on the ocean are highly unsustainable, and patterns of resource exploitation at sea are deeply inequitable. This article assesses whether the objectives encapsulated in the UN's Sustainable Development Goal for the ocean are well equipped to respond to these challenges. It will argue that the approach underpinned by the SDG 14 is largely compatible, unfortunately, with 'business as usual.' SDG 14 is undoubtedly intended as a starting point rather than a final destination; but it is nevertheless important to be clear about how far we still need to travel on the road to oceanic justice. Most significantly, SDG 14 leaves several key challenges inadequately addressed or simply unaddressed. It fails to specify adequate principles for the fair sharing of benefits and burdens flowing from the ocean, including the burdens of tackling pressing environmental problems. Neither does it address the underlying causes of inequality in the ocean economy. It neglects to properly address, furthermore, the fragmented institutional context which significantly impedes effective action to advance the goals of justice and sustainability at sea. Finally, whereas SDG 14 correctly identifies a series of necessary reforms to the ocean economy, it fails to engage with important issues of transitional justice which will arise if these policies are implemented. Vital first step though it is, promoting a just and sustainable ocean will require us to set our sights considerably higher than the targets endorsed as part of SDG 14

\section{Introduction: The Challenge of Ocean Justice}

In virtue of the vital ecosystem functions it performs, the ocean is hugely important to the future of our planet. It is also a major source of wealth and well-being, and will only grow in significance as pressure on land-based natural resources intensifies. But the ocean faces major challenges, which threaten to degrade its health and its ability to continue to support the lives and livelihoods of people and other species. Among the most prominent threats are ocean warming - which leads to rises in sea level and ocean acidification, as well as the growth of 'hypoxic' or dead zones at sea; pollution from plastic, agricultural run-off and fuel leakage; overfishing and other destructive fishing practices; mineral and petrochemical exploitation on the seabed, the environmental consequences of which are not well understood; and the introduction of invasive species into new areas, chiefly through the ballast water released by ships across our globe. At the same time, as new and highly capital-intensive forms of resource exploitation gather pace, the ocean threatens to become a driver of still greater global inequality, in which less technologically-advanced countries are left behind in the race to consume finite oceanic resources.

These overlapping problems combine to generate two major social and political challenges. First, how can environmental problems at sea be adequately responded to, in order to ensure a sustainable future for the $71 \%$ of our planet covered by water? Second, how can growing inequalities in the ocean economy be arrested and even reversed, so that a sustainable 'blue' economy comes to be a driver of greater equality rather than inequality? These twin challenges are key to achieving justice in the ocean - an arena which has, unfortunately, been largely neglected by philosophers and political theorists since the famous debates on the open and closed seas which took place during the seventeenth century (see e.g. Grotius, 1609). ${ }^{1}$ This article will examine how effective some recent moves on the part of the international community - and especially the promulgation of a dedicated Sustainable Development Goal for the ocean - are likely to be in responding to these twin challenges of ocean justice. Its conclusion will be that, though the greater attention paid at the international level to the future of the ocean is welcome, the approach underpinned by the Sustainable Development Goal for the ocean is largely compatible with 'business as usual,' that it will not bring about a sustainable ocean economy, and that it leaves unaddressed some of the foremost obstacles to achieving ocean justice. An adequate approach will require us to set our sights much higher.

Ocean Justice on the Agenda 
The second decade of our century brought increasing acceptance of the urgency of promoting just and sustainable ocean governance. In 2012 the United Nations Conference on Sustainable Development (known as 'Rio +20 ') identified the ocean as one of seven global priority areas for sustainable development, and called for immediate action to tackle climate change and acidification, declining fish stocks, and habitat and biodiversity loss. ${ }^{2}$ The same decade saw the inauguration of the annual UN Ocean Conferences, and of a regular series of UN reports on the state of oceanic health: the World Ocean Assessments. These are supported by a Group of Experts, with input from hundreds of scientists, and in their commitment to regularly assessing human impacts on the ocean they will in some respects parallel the climate reports released periodically by the Intergovernmental Panel on Climate Change. ${ }^{3}$ UNESCO, for its part, announced plans in 2017 for a dedicated Decade of Ocean Science for Sustainable Development, ${ }^{4}$ heralded by a mission statement called The Science We Need for the Ocean We Want. $^{5}$

But perhaps the most important development of all occurred in 2015, when the United Nations General Assembly adopted a set of 17 'Sustainable Development Goals' (SDGs) to be met by the year 2030. Among them are the goals of ending severe poverty and hunger, building strong and peaceful institutions, and reducing national and global inequalities. Each of these SDGs has a number of targets, along with dedicated performance indicators according to which success or failure can be measured, and many of which are intended to be satisfied before 2030 . Crucially, one of the 17 major goals refers exclusively to the ocean - the first time the international community has formally adopted a set of objectives for the future of the blue part of our planet. SDG 14 is labelled 'Life Below Water,' and aims to 'Conserve and sustainably use the oceans.' It includes numerous targets, as follows: ${ }^{6}$

\begin{tabular}{|l|l|l|}
\hline Target & Description & To be measured by \\
\hline 14.1 & $\begin{array}{l}\text { By 2025, prevent and significantly reduce marine } \\
\text { pollution of all kinds }\end{array}$ & $\begin{array}{l}\text { Index of coastal eutrophication and } \\
\text { floating plastic debris density }\end{array}$ \\
\hline 14.2 & $\begin{array}{l}\text { By 2020, sustainably manage and protect marine and } \\
\text { coastal ecosystems ...including by strengthening } \\
\text { their resilience, and take action for their restoration } \\
\text { in order to achieve healthy and productive oceans }\end{array}$ & $\begin{array}{l}\text { The proportion of countries' Exclusive } \\
\text { Economic Zones managed using } \\
\text { ecosystem-based approaches }\end{array}$ \\
\hline 14.3 & $\begin{array}{l}\text { Minimize and address the impacts of ocean } \\
\text { acidification }\end{array}$ & $\begin{array}{l}\text { Average marine acidity measured at } \\
\text { representative sampling stations }\end{array}$ \\
\hline 14.4 & $\begin{array}{l}\text { By 2020, effectively regulate harvesting and end } \\
\text { overfishing, illegal, unreported and unregulated } \\
\text { fishing and destructive fishing practices and } \\
\text { implement science-based management plans, in }\end{array}$ & $\begin{array}{l}\text { Proportion of fish stocks held within } \\
\text { biologically sustainable levels }\end{array}$ \\
\hline
\end{tabular}

\begin{tabular}{|c|c|c|}
\hline & $\begin{array}{l}\text { order to restore fish stocks in the shortest time } \\
\text { feasible }\end{array}$ & \\
\hline 14.5 & $\begin{array}{l}\text { By } 2020 \text {, conserve at least } 10 \text { per cent of coastal and } \\
\text { marine areas }\end{array}$ & $\begin{array}{l}\text { Geographical coverage of Marine } \\
\text { Protected Areas }\end{array}$ \\
\hline 14.6 & $\begin{array}{l}\text { By } 2020 \text {, prohibit certain forms of fisheries subsidies } \\
\text { which contribute to overcapacity and overfishing, } \\
\text { eliminate subsidies that contribute to illegal, } \\
\text { unreported and unregulated fishing and refrain from } \\
\text { introducing new such subsidies, recognizing that } \\
\text { appropriate and effective special and differential } \\
\text { treatment for developing and least developed } \\
\text { countries should be an integral part of the World } \\
\text { Trade Organization fisheries subsidies negotiation }\end{array}$ & $\begin{array}{l}\text { Progress by countries in implementing } \\
\text { international instruments aiming to } \\
\text { combat illegal, unreported and } \\
\text { unregulated fishing }\end{array}$ \\
\hline 14.7 & $\begin{array}{l}\text { By } 2030 \text {, increase the economic benefits to small } \\
\text { island developing States and least developed } \\
\text { countries from the sustainable use of marine } \\
\text { resources, including through sustainable } \\
\text { management of fisheries, aquaculture and tourism }\end{array}$ & $\begin{array}{l}\text { Sustainable fisheries as a percentage of } \\
\text { GDP in small island developing states } \\
\text { and least developed countries }\end{array}$ \\
\hline
\end{tabular}

Source: United Nations (2016) Transforming Our World: The 2030 Agenda for Sustainable Development (New York: United Nations).

The establishment of SDG 14 is a hugely valuable step forward, prompting much-needed discussion of the future of the ocean, and signalling its importance to the future of our world more generally. The various targets recognise some of the major challenges faced in the contemporary ocean, including climate change, overfishing, and pollution. They also suggest a concern for the socio-economic dimensions of ocean politics, with an explicit focus upon the distinctive positions of the least developed countries, and small island states. The SDGs have since won further institutional support. In June 2017, the United Nations held its first Ocean Conference in New York. This led, the following month, to the adoption of General Assembly Resolution 71/312, entitled Our Ocean, Our Future. This Resolution is 'mobilized by a strong conviction that our ocean is critical to our shared future and common humanity in all its diversity.' It declares, further, that the international community is 'committed to halting and reversing the decline in the health and productivity of our ocean and its ecosystems and to protecting and restoring its resilience and ecological integrity. We recognize that the well-being of present and future generations is inextricably linked to the health and productivity of our ocean. ${ }^{7}$

As the United Nations has emphasised, there are crucial interdependencies between SDG 14 and other Goals relating to, for instance, the eradication of poverty, an end to hunger, the promotion of sustainable development, and the reduction of inequality (see Griggs et al, 2017). ${ }^{8}$ 
Meeting those other goals will both depend upon, and in turn facilitate, progress towards ocean justice. The Resolution Our Ocean, Our Future also emphasises both the interlinked nature of the targets of SDG 14, and the links between SDG 14 and other SDGs. This recognition speaks in favour of what has been called the 'integration' of concerns about ocean justice into broader debates about global justice. Integrationist theories suggest that fair access to benefits and burdens in one domain - such as the ocean economy, or international trade, or natural resource governance - should not be determined in isolation, but rather must be determined with an eye to how people are faring in general. As a result decisions will often be made with an eye to correcting for wider background injustices (Caney, 2012). A good example would be climate justice: fair mitigation policies should not push poor communities further into poverty, and to the contrary should open up new opportunities for pro-poor development. This integrationist insight is important in the context of ocean justice too, because against a background of massive inequality even ensuring strictly equal access to the ocean's resources is not sufficient for achieving justice. To the contrary, justice requires that we take the opportunities offered by the ocean economy to narrow global inequalities, even if this means giving the least advantaged preferential access to its resources (Armstrong, 2017). It can also demand that we take positive steps to increase the participation of those who have been relatively marginalised and disempowered. For the United Nations to explicitly raise the question of how SDG 14 can support other global Goals, such as SDG 10 (which aims to 'reduce national and global inequality'), and vice versa, is therefore a promising step.

The same arguments should be applied to burden-sharing problems in the contemporary ocean. Vital conservation projects - whether this means the designation and enforcement of Marine Protected Areas, the protection and restoration of coral reefs, or the clean-up of pollution or spillages - will involve significant costs. These will certainly include the direct costs incurred in activities like clean-up, monitoring and enforcement; but they may well include significant opportunity costs too. For instance, the establishment of Marine Protected Areas, as well as efforts to reduce subsidies and overcapacity in the global fishing industry, will mean that some people will no longer be able to fish in the same places, or with the same intensity, and may therefore lead to significant losses of income. Just as benefits should be shared with an eye to background levels of advantage and disadvantage, the allocation of burdens should also avoid exacerbating global inequalities, and if possible help to ameliorate them. In this respect our situation when it comes to ocean conservation challenges parallels (and of course partly overlaps with) the multifaceted problem of fairly responding to climate change. Dealing effectively with climate change is also going to mean that many actors will incur significant costs. But in a world in which the advantaged could easily absorb these costs without incurring excessive setbacks to their well-being, whereas the least advantaged face other pressing problems (including, not least, escaping from poverty), to load burdens onto the shoulders of the latter should be seen as impermissible (Shue, 2014; Moellendorf, 2014). Our preferred method of sharing burdens - in the case of climate change and in the case of ocean conservation problems too - should foreground, therefore, a concern with broader global inequalities. One critical challenge here is to ensure that the transition to a sustainable ocean does not come at the expense of the legitimate development aspirations of the least advantaged.

Highlighting the important connections between ocean justice and goals of global justice more broadly is, then, one of the most important contributions of the SDG approach. But for all that it marks a significant advance, the principal question this article will raise is whether SDG 14, including its various targets, makes sufficient progress in moving us closer to a just and sustainable ocean economy. The SDGs are not, to be sure, intended to eradicate all forms of global injustice at one fell swoop, and they should not be treated as if they were, or were even intended to be, comprehensive accounts of the demands of justice. They represent starting points, upon which further progress might be incrementally built. The SDGs were also the result of international negotiation, and this process no doubt often leads to some watering-down of aspiration. We might nevertheless say - with some justification - that having global goals for the future of the ocean is an enormously worthwhile step, not least since it recognises that there should be collective social, economic and environmental aspirations for the ocean economy, and that sustained international cooperation will be required in order to deliver on them.

Nevertheless, we face profound and urgent challenges in the ocean economy, and it is important to be clearsighted about how far we are away from ocean justice, and how much closer the targets adopted alongside SDG14 would really take us. Notwithstanding the fact that the promulgation of a dedicated global goal on the ocean economy is a very worthwhile step, my claim will be that the targets collected under SDG 14, considered along with the specific performance indicators attached to them, are in many respects insufficiently ambitious, not least in the face of looming social and environmental crises at sea. ${ }^{9}$ Moreover, they fail to recognise, never mind present solutions to, some of the most formidable obstacles to justice. When these global goals are revisited for the period 2030-2045, there is an opportunity to be more ambitious. But a first step is to recognise how far the targets associated with SDG14 fall short of delivering on ocean justice. 
I will outline four major shortcomings of the approach taken by SDG 14, and the accompanying Resolution Our Ocean, Our Future, which suggest that the Goal must be seen as a modest beginning rather than an end on the voyage to ocean justice. The first shortcoming involves a failure to specify adequate principles for the fair sharing of benefits and burdens flowing from the ocean, including the burdens flowing from the need to respond to pressing environmental challenges. The second, related, shortcoming involves a failure to address the underlying causes of inequality in the ocean economy, and suggests that SDG 14 will do little to bring about substantial long-term change within the ocean economy. The third shortcoming arises from a failure to properly address the fragmented institutional context which characterises contemporary ocean governance, and which significantly impedes effective action to advance the goals of justice and sustainability. Fourth and finally, whereas SDG 14 correctly identifies a series of necessary reforms to the ocean economy - including the reduction of subsidies and overall fishing effort, and the designation of larger and more effective Marine Protected Areas - it fails to address important issues of transitional justice which will arise if these vital policies are actually implemented. Relatedly, SDG 14 does not seriously engage with the many adaptation issues which will arise in the context of a rapidly warming, acidifying, and rising ocean..$^{10}$ Promoting a just and sustainable ocean will therefore require that we set our sights considerably higher than the goals endorsed under SDG 14. A vital first step on the way to ocean justice, though, is to be clear about the justice gaps left by the SDG approach.

\section{Fairly Sharing Benefits and Burdens}

If the various SDGs are mutually connected and interdependent, then one of the criteria we should bear in mind when assessing SDG 14 is whether acting on it actually promises to narrow global inequalities as a whole. Narrowing both national and global inequalities, after all, is the objective of SDG $10 .{ }^{11}$ Here there are early signs of promise, since SDG 14.7 aims precisely to increase the economic benefits flowing from the ocean economy to small island states (SISs) and the least developed countries (LDCs). The description of target 14.7 does not clarify, however, whether progress is to be identified by measuring absolute levels of benefits, or comparative levels. To answer this question we need to turn to the specific performance indicator associated with it. Progress, the indicator makes clear, is to be measured by the proportion of GDP which emanates from the fishing industry in all states, including the least developed countries and small island states. As a measure of fair benefit-sharing, however, this possesses two significant drawbacks.
The first is that this normative standard is much too easy to satisfy. Depending on the direction of travel of a developing country's GDP, this target could be satisfied in a country where gains from fishing in particular were barely rising, if at all. In fact the standard could be satisfied in a situation where the absolute gains from fishing were declining: this could happen in a recession, for instance, so long as overall GDP declined faster than the contribution from the fishing sector. ${ }^{12}$ This is inadequate: at the very least, satisfying SDG 14 should demand that the absolute gains flowing to the least advantaged increase over time.

Second, the indicator says nothing about a country's gains relative to the rest of the world, or relative to developed countries in particular. Meeting SDG 14.7 is, in fact, compatible with the gains to LDCs and SISs deteriorating in proportion to the gains flowing to developed countries, so long as the gains to the LDCs and SISs nevertheless grow as a proportion of their respective GDPs. SDG 14 could be met, that is, in the presence of widening inequalities in the ocean economy. By failing to link progress to the comparative allocation of benefits, SDG 14 avoids the question of whether achieving greater gains to the disadvantaged might require developed country industries to reduce or constrain the income they gain from fishing. This avoidance might be justifiable if we can safely assume that the overall gains from fishing will continue to grow over time. But that assumption should not be taken for granted. If the potential or actual gains from fishing are limited, questions about their relative distribution become much more pressing. SDG 14.7 sidesteps those questions.

A further significant problem with target 14.7 is that it is too narrow in scope. Indeed the specific indicator associated with target 14.7 is particularly narrow, since it refers to financial gains from fishing alone. Even assuming for the sake of argument that an exclusive focus on the fishing industry were justifiable, this indicator would be too narrow. By focusing on financial gains from fishing, 14.7 does not require progress, for example, in safeguarding the interests of people in countries highly dependent upon seafood for their basic nutrition. In this respect targets 14.4 and 14.6 will surely help considerably, by promoting the sustainability of fish stocks and reducing illegal fishing. Nevertheless, it is regrettable that SDG 14 does not engage with questions about the ultimate destination of harvested fish. Given that neglect, it appears that SDG 14 could be satisfied in a context where fishing in developing countries remained highly export-oriented, even if this caused setbacks to the basic food security of local people. Once more, this lacuna suggests a failure to take the mutual interdependence of the SDGs sufficiently seriously. SDG 2 aims to end world hunger, by ensuring that everyone has access to safe and nutritious food all year round..$^{13}$ If so, then addressing the continual flow of fish from some of the world's poorest countries to markets in the developing world ${ }^{14}$ ought to 
be a priority. Doing so would require serious attention to the capacity of developing-world fishing industries, as well as their states' capacities to enforce sustainable limits on fishing (see below)

Aside from fishing, there are many other sectors of the marine economy where promoting the (comparative as well as absolute) benefits flowing to people in the developing world ought to be a priority. By focussing on income from fishing, aquaculture, and tourism, by contrast, target 14.7 excludes many important sectors of the ocean economy, including minerals, shipping, energy, and marine genetic resources. Consider the last of those examples. The exploitation of genetic resources within the High Seas is as yet largely unregulated. One of the key decisions which will have to be made in the coming years is what form, if any, benefit-sharing mechanisms attached to the exploitation of marine genetic resources will take. Whilst a new regime for 'biodiversity beyond national jurisdiction' is being debated within the United Nations, an important moral compass would be a commitment to turning all forms of resource exploitation within the ocean to the task of narrowing global inequalities. If we take the interconnectedness of the SDGs seriously, then we need to be much more serious about finding ways for the ocean economy to spur catch-up development.

Thus far in this section I have focused on the benefits flowing from the ocean economy. But there are also crucial questions to be asked about the proper distribution of burdens, not least in the context of pressing environmental challenges. Recalibrating our demands upon the ocean, whether as a source of resources or as a sink for waste, will involve the incurring of many kinds of costs. These will include the costs of protecting precious resources from various threats. They will also include, in many cases, the costs of restoring ecosystems in light of prior degradation, as target 14.2 appears to demand. Finally, these will include opportunity costs, as actors are asked to refrain from exploiting resources from which they have benefited in the past. Examples would include the losses incurred by fishers who are asked not to fish in Marine Protected Areas, or who are required to abandon the most destructive forms of harvesting. ${ }^{15}$ But who should pick up these conservation costs? On this question, SDG 14 is silent. The Resolution Our Ocean, Our Future does perhaps offer one clue, by suggesting that when implementing the goal we should take 'into account different national realities, capacities and levels of development. ${ }^{16}$ That claim suggests a key role should be played by considerations of capacity or ability to pay. A defensible account of fair burden-sharing will indeed give weight to those considerations. But as an approach to fair burden-sharing, this is incomplete. A plausible account of burden-sharing will also make space for considerations of contribution to the problem, and to patterns of benefits flowing from conservation. Without a fuller account of how these principles can be integrated, SDG 14 does not offer a complete guide to action. ${ }^{17}$

\section{The Drivers of Oceanic Inequality}

There are three major drivers of inequality in the ocean economy. These relate to geography (mediated by political choices), access to capital (including extractive technology), and administrative capacity. If the ocean economy is to be a just one, in which the least advantaged are given genuine opportunities to catch up with people living in more advantaged countries, it is vital that each of these drivers of oceanic inequality receives sustained attention. SDG 14 , however, fails to give these drivers the required attention, and does not advance measures which would substantially ameliorate them. As such, delivering on SDG 14 would not shift the fundamental inequities in the ocean economy.

Consider first geographical differences. The United Nations Convention on the Law of the Sea (UNCLOS) of 1982 ushered in a period of extensive enclosure of the oceans, the effects of which were deeply unequal. For the first time, states were able to claim Exclusive Economic Zones (EEZs) extending for two hundred nautical miles out to sea, and continental shelves extending for two hundred miles or in many cases further along the seabed. Within these zones, states now possess exclusive rights over natural resources. The reason this process has been inegalitarian is that some states do not possess coastlines, and now find themselves effectively shut out of access to many resources, including the vast majority of the world's fish. Moreover, in many cases overseas protectorates emanating from the colonial era have significantly bolstered overall entitlements. The 'big six' countries (Britain, the United States, France, New Zealand, Australia and Russia) possess 54 million square kilometres of EEZs, of which 39 million square kilometres are derived from overseas possessions or protectorates. To give but one example, the Pitcairn Island group (a British Overseas Protectorate) has a population of around 40 people, but commands an EEZ of 836,000 km. ${ }^{2}$ This is similar in size to China's total EEZ (Nolan, 2013, 82), which must serve a population of well over a billion. In Pitcairn, however, only the approximately 40 islanders are permitted to fish. ${ }^{18}$

Given that both SDG 14 and the Resolution Our Ocean, Our Future remain committed to the UNCLOS framework, and declare an intention to avoid pursuing policies which would undermine that legal settlement (see below), it is clear that the reality of substantial oceanic enclosure is taken as the status quo rather than being problematized as a potential impediment to progress. ${ }^{19}$ This is regrettable. But even if the fundamental division of oceanic territory is to 
be treated as the default, the formulation of SDG 14 represented an opportunity to mitigate some of its effects on the prospects of people living in various parts of the world. This chance too was unfortunately missed. UNCLOS contains several references to the distinctive position of 'geographically disadvantaged countries' (GDCs) which must rely on other countries for access to the sea. Those references have not, however, translated into meaningful progress to date for GDCs seeking to engage more fully in the oceanic economy. Aside from a few countries in Europe - where any potential disadvantages emanating from landlocked status are mitigated by good transport links, the presence of several large, wide waterways, cordial political relations, and a common market - landlocked countries have struggled to escape from 'underdeveloped' status. As Paula Casal and Nicole Selamé have argued, SDG 14 represents a missed opportunity for these countries. SDG 14 could have sought to promote ways to improve physical access to the sea for landlocked countries, for example by exploring projects for land bridges, tunnels, land-swaps or other innovative methods of facilitating direct access (Casal and Selamé, 2015). It could also have explored ways of promoting the participation of GDCs in the fishing industry, or the ocean minerals sector. But aside from its references to small island states, the goal of tackling specifically geographical disadvantage is not taken up by SDG 14.

I have also suggested that access to capital is a key issue for many developing countries seeking to engage with the ocean economy. Reducing subsidies (as demanded by target 14.6) will do much to give coastal developing countries space to develop their own fisheries sectors (OkaforYarwood, 2019). So too will reducing illegal, unreported and unregulated fishing (target 14.4), which also threatens the livelihoods and basic nutritional interests of many people in the developing world. But clearing space for indigenous marine activity is not the same as enhancing the capacity to take advantage of it. In many cases local industries will continue to struggle to reap the potential benefits of the ocean economy, and a prominent reason is that many ocean industries are so highly capital-intensive. That is evident in the case of mineral or petrochemical extraction from the seabed under states' EEZs, which the least developed countries are poorly placed to benefit from; instead they are likely to reap the relatively meagre benefits to be gained by outsourcing exploitation to multinational corporations. Engaging in the exploitation of marine genetic technology is also associated with enormous start-up costs and is likely to bring far greater benefits to countries with better scientific and technical infrastructure (Broggiato et al, 2014. See also Le Blanc et al, 2017: 21). Narrowing these gulfs in access to productive capital should be an important goal of ocean justice. Enhancing the technological capacity of developing-country marine industries is not, however, a specific objective of SDG 14. Indeed the sharing of technology is not mentioned in anywhere of the performance indicators associated with SDG 14, although it appears to be instrumentally important to achieving a number of its targets. The targets do not discuss how technology could be diffused, and who if anyone might be obliged to bear the costs of that diffusion (Morgera and Ntona, 2018). In this context, it has been argued that building up local and sustainable marine industries could be an important goal for overseas development aid. In practice, however, aid dedicated specifically to enhancing developing countries' ability to benefit from the ocean economy appears to be declining in many parts of the world, rather than growing, even as a proportion of development aid (Blasiak and Wabnitz, 2018). This trend will diminish the potential for the ocean economy to contribute to the goal of reducing global inequalities.

Finally, let us consider the issue of administrative capacity. Target 14.4 aims for states to recover fish stocks by ending unsustainable harvesting practices. Targets 14.2 and 14.5, meanwhile, enjoin states to take an ecosystem-based approach to conservation within their EEZs, and to extend and enforce a network of Marine Protected Areas. Finally, meeting target 14.6 requires states to tackle illegal, underreported and unregulated fishing, which at present seriously undermines many developing countries' ability to maintain sustainable fisheries (Okafor-Yarwood, 2019). The problem is that all of these activities will require a degree of administrative capacity which is absent in many parts of the developing world. To make genuine progress, SDG 14 should focus upon methods of enhancing enforcement capacity, rather than simply encouraging enforcement. One challenge here is the need to improve the general administrative and fiscal capacities of some developing states (see Armstrong, 2019a, chapter 3). Another is the need to enable states to benefit from the revolution in remote monitoring which is currently taking place in the world's oceans. The expansion and improvement of vessel tracking technology, including remote sensing and satellite technology, the emergence of drones, and the enhancement of our ability to harness 'big data' have all contributed to much improved prospects for monitoring and controlling the activities of the fishing industry (Miller, 2010). But the required technology may still be out of the reach of the least developed countries. SDG 14 does not address this important question of access to remote monitoring technology, but it is picked up in accompanying documents. The Resolution Our Ocean, Our Future emphasizes 'the need to enhance scientific knowledge and research, enhance capacity-building at all levels [and] mobilize financial resources from all sources. ${ }^{20}$ The document Transforming Our World, which accompanies and introduces all 15 SDGs, meanwhile, addresses the need to support sustainable fisheries in developing countries (United Nations 2016, paragraphs 24 and 27). SDG 17 also discusses the financing and capacity 
building necessary in order to deliver on the other SDGs. But SDG does not adopt any specific targets for the sharing of monitoring technology, and so as it stands considerably more detail is required both in terms of the mechanisms for building capacity, and in terms of how the relevant burdens are going to be shared.

\section{Institutional Fragmentation}

Contemporary ocean governance is a patchwork. ${ }^{21}$ The ocean is legally divided into territorial seas, Exclusive Economic Zones, continental shelves, the High Seas, and the deep seabed, each of which is governed by its own principles and actors. Within the High Seas, a number of different actors have relevant legal competence, including Regional Fisheries Management Organizations (RFMOs), the International Maritime Organization, and, at the Southern reaches of the ocean, the Antarctic Treaty System. In the years since UNCLOS, a number of resource governance principles have emerged and, to varying degrees, been recognised within international law - including the ecosystem management approach and the precautionary principle. The ecosystem management approach recognises the marine environment as a complex, interlocking system of organisms and processes. In response, it recommends integrated forms of governance which are capable of maintaining the 'health,' and building the long-term resilience, of overall ocean ecosystems (Long et al, 2015). The precautionary approach recognises the many uncertainties involved in the marine ecosystem, as well as the possibility of unexpected tipping points and cascade effects. It therefore recommends that planned human activities err on the side of caution, and that those who propose potentially damaging activities should bear the burden of proof in identifying and if necessary mitigating potential risks (Constanza et al, 1998). It is not obvious, however, that the existing institutional architecture under the UNCLOS regime is capable of doing justice to such principles. The division between different actors, each with their own priorities and sectoral (and sometimes species-specific) missions, makes effective governance of complex and interdependent ecosystems tremendously difficult. Most strikingly, according to one prominent scholar of the Law of the Sea, there is 'virtually no coordination' between existing institutions with competence on the High Seas. To the contrary, 'The culture, processes and epistemic communities of each of these institutions are entirely different. Conservation arguments raised in one institution carry little, if any, weight in the others' (Freestone, 2012, 1).

It would be unrealistic to expect SDG 14 itself to resolve these problems. But it is important nevertheless to be clear about what SDG 14 is able to achieve, and what problems it leaves unaddressed. The Resolution Our Ocean, Our Future emphasises 'the need for an integrated, interdisciplinary and cross-sectoral approach, as well as enhanced cooperation, coordination and policy coherence at all levels ${ }^{22}$ when addressing conservation challenges. But this is a call for greater cooperation between existing institutions: SDG 14 does not seek to remedy the fragmented structure of contemporary oceanic governance, only to improve communication and coordination within that structure. SDG 14.4, for instance, aims to increase the proportion of fish stocks which are harvested within sustainable levels. But whilst it covers stocks within EEZs, the indicator exempts stocks under RFMO management on the High Seas. The desire to avoid constraining the decisions of RFMOs is also evident in the Resolution Our Ocean, Our Future. This Resolution insists upon the need to ensure that actions taken to implement SDG 14 do not 'duplicate or undermine existing legal instruments, arrangements, processes, mechanisms or entities. ${ }^{23}$ This might be a valuable principle if existing instruments and entities were broadly effective. But if just and sustainable ocean governance requires institutional innovation, the injunction against undermining the existing structure becomes an impediment to progress.

It is likely that achieving just and sustainable ocean governance will mean displacing the exclusive role of states as the primary - or even sole - enforcers of the Law of the Sea on the High Seas. Two examples can help to illustrate this need. First, effective governance of the High Seas will require reforms to the RFMO system in which states can pick and choose which conservation measures will apply to their fishing activities. One central question which is currently being discussed in the context of the negotiations for a new legal instrument for Biodiversity Beyond National Jurisdiction relates to agency and authority: who should be entitled to propose, designate, monitor and enforce Marine Protected Areas on the High Seas? At present, MPAs are largely notable by their absence in the Area Beyond National Jurisdiction, because they require coordination between states with different and often opposed interests. At the time of writing, only a little over one percent of the High Seas is incorporated into protected areas. ${ }^{24} \mathrm{~A}$ prime counterexample is the enormous Ross Sea Marine Protected Area in the Southern Ocean. The Ross Sea MPA was established by the parties to the Antarctic Treaty System, and now protects the least disturbed area anywhere in the world's ocean. But other proposals for MPAs in the Southern Ocean have been vetoed under the Treaty System's consensus-based decision procedure, and as a result of objections from some member countries even the Ross Sea MPA covers barely a third of the area originally proposed. It has not, furthermore, led to a significant decline in fish catch in the area..$^{25}$ Meanwhile - as is the case 
elsewhere on the High Seas - Antarctic MPAs will of course only be binding on states which are parties to them.

A central problem which plagues efforts to designate MPAs outside of individual states' territorial seas is the practice of 'exclusive flag state jurisdiction,' under which vessels' activities are only to be constrained by the state under which they are 'flagged' (Blanchard, 2017, 328). ${ }^{26}$ In the case of fishing this is a major impediment to progress, since a vessel whose state joins an RFMO, or which supports an MPA, can simply 'flag out' by registering with a state which recognises neither. But the practice of exclusive flag state jurisdiction is also an obstacle to justice in a second area: the protection of workers' rights at sea. The rights of fishers and seafarers are enshrined in a number of international legal instruments, and flag states have a duty to ensure that they are adequately protected in practice. But many states are unwilling or unable to apply these rules to seafarers working on the vessels which sail under their flags. To the contrary, so-called 'Flag of Convenience' states facilitate a race to the bottom in labour rights, functioning, effectively, as mobile exploitation havens for unscrupulous employers. In this case too a fully adequate response may require the emergence of a form of pooled international authority on the High Seas. In both cases, justice likely requires that we transcend, rather than treating as inviolate, the fragmented nature of governance on the ocean.

\section{Challenges of Transitional Justice}

The need to protect the ocean environment will require many people to alter - and often significantly reduce - the demands they place upon its ecosystems. Moreover, in a time of accelerating climate change, processes of acidification, ocean warming, and sea level rise will have major impacts upon the lives and livelihoods of millions of people across the world. In the first case, the need to prevent excessive environmental damage will require many people to make sacrifices. These might include actions to reduce carbon emissions, measures to reduce fishing effort or to avoid some of the most destructive fishing practices, or measures to reduce or eliminate environmental damage arising from seabed mining, to give but a few examples. In the second case, the ocean itself will impose costs upon many of us, as people are forced to relocate, or to find alternative sources of nutrition or income. In the most serious instances, basic rights to life and to subsistence will be seriously threatened. Many people will also be forced to adjust to life in new places many miles from home. We can call the first set of sacrifices 'prevention burdens,' since they involve efforts to avoid environmental damage, or to reduce its likely consequences. The second set of burdens can usefully be called 'impact burdens,' since here we are picking out the costs which any un-avoided environmental damage or change will impose upon us. ${ }^{27}$

An adequate account of ocean justice will help us to think about the proper allocation of both types of sacrifices. Although the Sustainable Development Goals do not, of course, attempt to provide a full account of oceanic justice, they nevertheless ought to recognise the existence of these burdens, and to provide at least some guidance as to how they can be either mitigated, or fairly shared. Fair sharing matters in itself. But a perception that costs are not being fairly allocated is also likely to hinder progress in meeting shared objectives.

SDG 14, however, does not appear to provide any guidance on the proper allocation of burdens. This is unfortunate, since at least some of the actions suggested by SDG 14 will themselves generate significant prevention burdens. A prime example is the transition within the fishing industry. SDG 14.4 and 14.6 rightly emphasise the goals of cutting back fishing effort, and reducing subsidies. Global fish catch has already declined since the mid-1990s, despite technological advances allowing vessels to capture fish more efficiently (Golden et al, 2016; Pauly and Zeller, 2016). The reason is no secret: an increasing proportion of stocks are now being fished beyond sustainable levels, meaning that catches exceed the reproductive ability of many individual species. Ecologists estimate that achieving sustainability in fish stocks would require an overall reduction in global fishing effort in the order of $40 \%$, which would suffice to take total effort back roughly to the levels of the 1990s (Ye, 2013, 179). Plausibly, rendering fishing effort sustainable would also require the phasing out of many of the most damaging fishing practices, including certain forms of bottom trawling, the use of longlines associated with the death of seabirds, and the use of poisons and explosives in fishing. The transition to less damaging methods would in itself be costly. But more significantly, the reduction in overall fishing effort could mean, it has been estimated, the loss of between twelve and fifteen million jobs (Ye, 2013, 180). In many parts of the developing world, coastal communities possess little in the way of social safety nets which might help cushion the blow to the livelihoods of those affected.

A similar point could be made about target 14.5, which aims to increase the coverage of Marine Protected Areas (MPAs). In the long term, the establishment of effective MPAs can help fishers, rather than hindering them. When protected from fishing, more individual fish are able to reach full maturity and hence spawn many more eggs, which typically disperse over long distances. MPAs acts as 'centres of production that radiate outward to surrounding fishing grounds' (Roberts, 2007, 365). As a consequence, the numbers of fish within an area can double or even quadruple after just a few years of protection, bringing significant gains to local fishers 
(ibid, 70). But in the short term, prohibitions on fishing can be very costly for individual fishers, especially in communities where alternative sources of employment, and meaningful government support, are thin on the ground. SDG 14.5 does not, however, address the question of how the necessary transitions can be managed without setbacks to the most basic interests of people currently engaged in, or dependent upon, fishing. This is in stark contrast to the first World Ocean Assessment, which explicitly recognises the need to address the transitional costs associated with rebuilding depleted fish stocks (United Nations, 2017, 18). SDG 14 focuses on the (important) environmental goal of protecting the ocean, but neglects the socio-economic dimensions of the necessary transitions. Might outsiders owe assistance to the affected communities? If so, of what type, and on what basis? These are important questions of justice, but they are not recognised, never mind resolved, by SDG $14 .^{28}$

There are also major impact burdens that we ought to seek to share fairly, or where possible to mitigate. Many of these are associated with climate change. For instance, increases in local oceanic temperatures are already leading to major shifts of many marine species away from the equator and towards the Poles, with major consequences for people who rely on them for their sustenance (United Nations, 2017, 20). Species with strong temperature preferences including tuna - are expected to alter their range most radically (ibid, 22). At present many Pacific island states rely heavily on income from selling access rights to tuna stocks. The loss of that income could have dramatic consequences for the provision of public services. Many other significant impacts of ocean warming will fall upon people and ecosystems located close to the shore. People living in coastal areas will be more vulnerable to extreme weather events as climate change accelerates the degradation of organic coastal defences such as coral reefs or mangrove swamps. Their livelihoods will be affected as carbon absorption spurs the growth of hypoxic or 'dead' zones within the ocean. Their lives will also be radically altered by the encroaching sea itself. By 2100, the World Ocean Assessment reports, we may have witnessed median sea level rises in the order of one metre above 1980-1999 levels (ibid, 21). Over 150 million people are estimated to live on land that is currently no more than one metre above sea level (ibid, 24). Sea level rises are therefore expected to have a serious impact upon the lives and livelihoods of many millions of people. In extreme cases - including low-lying atoll states such as Kiribati or Tuvalu - entire countries appear likely to disappear. Such communities may also lose their entitlements to EEZs, if international law continues to measure entitlements from the pre-climate change baseline. In other cases, vital farm land will be rendered infertile by the salinization of the water table, and rendered dangerous by increasingly common extreme weather events (Zacharias and Ardron, 2020, 171). Strikingly, however, SDG 14 does not engage with any of the impacts of climate change other than ocean acidification.

These probable impact burdens trigger a series of urgent normative questions. Do people whose livelihoods have been affected by ocean warming have claims to assistance or compensation from the international community? If so, precisely who are the relevant duty-bearers, and on what basis should costs be allocated between them? What rights do people who will lose their land because of sea level rises have? Who, if anyone, has a duty to bear the costs associated with granting them new forms of political membership? Should fishing (and general resource extraction) rights endure, or lapse, once a state has disappeared below water? ${ }^{29}$ These vital normative questions are not recognised by SDG 14, despite representing some of the most formidable challenges of ocean justice that we face today.

\section{Conclusions}

The proclamation of a global priority of ensuring the conservation and sustainable use of the ocean's resources is a tremendously valuable step, as is the attention which SDG 14 gives to increasing the benefits flowing from the ocean economy to the least advantaged countries. But whilst SDG 14 is a useful spur to reflection on the kind of oceanic future we want to achieve, the specific targets associated with the Sustainable Development Goal remain very minimalist in character. Recognising this is important if more substantial progress towards ocean justice is to be made over time. SDG 14 does not require us to ask fundamental questions about the distribution of benefits and burdens flowing from the ocean, or to engage with the disparities that generate inequality within the oceanic economy. Nor does it tackle the institutional fragmentation that in many cases stands as an obstacle to fairness and sustainability at sea, or the transitional challenges associated with a fair and sustainable future at sea. As such, the SDG 14 approach appears broadly compatible with 'business as usual' in the world's ocean. Clarifying these deficiencies has, however, been useful in identifying the challenges which an adequate account of ocean justice must face. It is to be hoped that political theorists and philosophers will fully engage with those challenges in the years to come.

${ }^{1}$ Rare exceptions which do discuss the ocean from a philosophical point of view include Armstrong $2018 \mathrm{~b}$ and Nine 2019 . 
${ }^{2}$ https://sustainabledevelopment.un.org/index.php?menu=1298. For discussion, see Campbell et al https://www.worldoceanassessment org

${ }^{4}$ https://en.unesco.org/ocean-decade

${ }^{6}$ SDG 14 also describes three 'means of implementation,' as follows: 14.A. "Increase scientific knowledge, develop research capacity and transfer marine technology...in order to improve ocean health and to enhance the contribution of marine biodiversity to the development of developing countries, in particular small island developing States and least developed countries." To be measured $b y$ : Proportion of total research budget allocated to research in the field of marine technology. 14.B. "Provide access for small-scale artisanal fishers to marine resources and markets." To be measured by: rights for small-scale fisheries. 14.C "Enhance the conservation and sustainable use of ococts access resources by implementing international law as reflected in UNCLOS, which provides the lega framework for the conservation and sustainable use of oceans and their resources." To be measured by: Number of countries making progress in ratifying, accepting and implementing through legal, policy and institutional frameworks, ocean-related instruments that implement international law.

7 Our Ocean, Our Future, Article 2, Article 5.

See https://www.un.org/ga/search/view doc.asp?symbol=A/RES/71/312\&Lang=E

${ }^{8}$ For more systematic analysis of the interconnections between SDG 14 and the other SDGs, see Schmidt et al 2017, and Le Blanc et al 2017.

A distinct, but in many ways justified, objection to many of the targets is that they are insufficiently

${ }^{10}$ Target 14.3 aims to reduce the extent of acidification, and its impacts. But the accompanying measure focuses on the reduction of acidification, and does not demand any specific measures to allow place.

12 This://sustainabledevelopment.un.org/sdg10

by any means, since scholars have often noted that fishing

${ }_{14}^{14}$ Developed countries are the destination for $85 \%$ of global fish exports. Swartz et al 2010: 1367.

${ }^{15} \mathrm{~F}$ For a fuller account of conservation as protection, restoration and non-exploitation, and an exploration of how the costs of each ought to be shared, see Armstrong 2017, chapter 10 .

${ }^{16}$ Our Ocean, Our Future, Article 7.

For such an integrated accolnt, see Armstrong 2018

${ }^{18}$ In 2010, the Pitcairn EEZ was designated a Marine Protected Area. All fishing is now prohibited, with the exception of subsistence fishing by Pitcairn Islanders. https://www.pewtrusts.org/en/researchand-analysis/fact-sheets/2015/03/he-pitcairn-islands

instrument for Biodiversity Beyond Nationa Jurisdiction will incorporate the same prohibition on undermining existing institutions. Blanchard 2017

${ }^{21}$ Our Ocean, Our Future, Article 12. dimensions: a lack of coordination between instruments and institutions, and the presence of gaps in coherent governance.

${ }_{22}^{2}$ Our Ocean, Our Future, Article 8.

${ }^{23}$ Our Ocean, Our Future, Article 11

${ }^{24} \mathrm{https} / / / \mathrm{www}$.protectedplanet.net/marine. Accessed $11^{\text {th }}$ July 2019

${ }^{26}$ Territorial seas stretch for twelve nautical miles from a state's coast. Within those waters, vessels can be subjected to the legal powers of the coastal state, if the latter so chooses. Within Exclusive Economic Zones, coastal states can enforce their resource rights over fishing activities. But they cannot enforce matter for flag states. On the High Seas, enforcement of any relevant laws or regulations is a matter for the flag state alone.
${ }^{27}$ For the distinction between prevention and impact burdens, see Alex McLaughlin, Climate Change thesis, University of Reading.

For an account of when and why outsiders might have a d
environmentally destructive practices, see Armstrong $2019 \mathrm{~b}$.

${ }^{29}$ For an argument that they should endure, see Armstrong and Corbett 2020.

\section{References}

Armstrong, Chris (2017) Justice and Natural Resources: An Egalitarian Theory (Oxford: Oxford University Press).

Armstrong, Chris (2018a) "Sharing Conservation Burdens Fairly," Conservation Biology 33.3: $554-560$.

Armstrong, Chris (2018b) "Resources Outside of the State: Governing the Ocean and Beyond," Philosophy Compass 13.11: e12545.

Armstrong, Chris (2019a) Why Global Justice Matters: Moral Progress in a Divided World (Cambridge: Polity).

Armstrong, Chris (2019b) "Decarbonisation and World Poverty: A Just Transition for Fossil Fuel Exporting Countries?" Political Studies: 0032321719868214.

Armstrong, Chris and Jack Corbett (2020) "Climate Change, Sea Level Rise and Maritime Baselines: Responding to the Plight of Low-Lying Atoll States," Global Environmental Politics, forthcoming.

Le Blanc, David et al (2017) Mapping the Linkages Between Oceans and Other Sustainable Development Goals: A Preliminary Exploration (New York: United Nations Division for Sustainable Development Working Paper 149).

Blanchard, Catherine (2017) "Fragmentation in High Seas Fisheries: Preliminary Reflections on a Global Oceans Governance Approach," Marine Policy 84: 327-32.

Blasiak, Robert, and Colette Wabnitz (2018) "Aligning Fisheries Aid with International Development Targets and Goals," Marine Policy 88: 86-92.

Broggiato, Arianna et al (2014) "Fair and Equitable Sharing of Benefits from the Utilization of Marine Genetic Resources in Areas Beyond National Jurisdiction: Bridging the Gaps between Science and Policy," Marine Policy 49: 176-85.

Campbell, Lisa et al (2013) 'Oceans at Rio+ 20,' Conservation Letters 6.6: 439-47.

Caney, Simon (2012) “Just Emissions,” Philosophy \& Public Affairs 40.4: 255-300.

Casal, Paula, and Nicole Selamé (2015) "Sea for the Landlocked: A Sustainable Development Goal?" Journal of Global Ethics 11.3: 270-79. 
Cormier, Roland and Michael Elliott (2017) "SMART Marine Goals, Targets and Management - Is SDG 14 Operational or Aspirational, Is 'Life Below Water' Sinking or Swimming?" Marine Pollution Bulletin 123.1-2: 28-33.

Costanza, Robert, et al (1998) "Principles for Sustainable Governance of the Oceans," Science 281.5374: 198-99.

Freestone, David (2012) "The Final Frontier: The Law of the Sea Convention and Areas beyond National Jurisdiction," Proceedings of the 2012 Law of the Sea Institute Conference on Securing the Ocean for the Next Generation (Berkeley: Law of the Sea Institute), 1-15.

Golden, Christopher et al (2016) "Fall in Fish Catch Threatens Human Health," Nature News 534-7607.

Griggs, David et al (2017) A Guide to SDG Interactions: From Science to Implementation (Paris: International Council for Science).

Grotius, Hugo (1609 / 2004) “The Free Sea," in The Free Sea, translated by Richard Hakluyt (Indianapolis: Liberty Fund)

Jul Larsen, Eyolf (2003) "Analysis of Effort Dynamics in the Zambian Inshore Fisheries of Lake Kariba," in Jul Larsen et al, Management Co-management or No Management? Major Dilemmas in Southern African Freshwater Fisheries. Fisheries Technical Paper $426 / 1$ \& (Rome: Food and Agriculture Organization).

Long, Rachel et al (2013) "Key Principles of Marine Ecosystem-Based Management," Marine Policy 57: 53-60.

Miller, Denzil (2010) "Occupying The High Ground: Technology And The War On IUU Fishing," in Davor Vidas (ed) Law, Technology and Science for Oceans in Globalisation (Leiden: Brill Nijhoff): $75-99$.

Moellendorf, Darrel (2014) The Moral Challenge of Dangerous Climate Change (Cambridge: Cambridge University Press).

Morgera, Elisa and Mara Ntona (2018) "Linking Small-scale Fisheries to International Obligations on Marine Technology Transfer," Marine Policy 93: 295-306.

Nine, Cara (2019) "Rights to the Oceans: Foundational Arguments Reconsidered," Journal of Applied Philosophy 36.4: 626-642.

Nolan, Peter (2013) “Imperial Archipelagos," New Left Review 80: 77-95.

Okafor-Yarwood, Ifesinachi (2019) "Illegal, Unreported and Unregulated Fishing, and the Complexities of the Sustainable Development Goals (SDGs) for Countries in the Gulf of Guinea," Marine Policy 99: 414-22.

Pauly, Daniel and Dirk Zeller (2016) "Catch reconstructions reveal that global marine fisheries catches are higher than reported and declining," Nature Communications 7.10244: 1-9.
Roberts, Callum (2007) The Unnatural History of the Sea: The Past and Future of Humanity and Fishing (London: Gaia), p.365. Schmidt, Stefanie et al (2017) 'SDG 14 - Conserve and Sustainable Use the Oceans, Seas and Marine Resources for Sustainable Developm (' is Isgs, David (et al eds) A Gide to SDG 218 .

Shue, Henry (2014) Climate Justice: Vulnerability and Protection (Oxford: Oxford University Press).

Swartz, Wilf et al (2010) "Sourcing Seafood for the Three Major Markets: The EU, Japan and the USA," Marine Policy 34: 1366-73.

United Nations (2016) Transforming Our World: The 2030 Agenda for Sustainable Development (New York: United Nations).

United Nations (2017) First Integrated Global Ocean Assessment: The World Ocean Assessment (Cambridge: Cambridge University Press).

Ye, Yimin (2013) 'Rebuilding Global Fisheries: The World Summit Goals, Costs and Benefits," Fish and Fisheries 14.2: 174-85.

Zacharias, Mark and Jeff Ardron (2020) Marine Policy: An Introduction to Governance and International Law of the Oceans (Abingdon: Routledge) 